\title{
KRIGAGEM DOS INDICADORES APLICADA A MODELAGEM DAS TIPOLOGIAS DE MINÉRIO FOSFATADOS DA MINA F4
}

\author{
S. A. BRAGA* e J.F.C. L. COSTA \\ Universidade Federal do Rio Grande do Sul \\ silvaniabraga@hotmail.com*
}

Artigo submetido em dezembro/2015 e aceito em fevereiro/2016

DOI: $10.15628 /$ holos.2016.3870

\begin{abstract}
RESUMO
A caracterização do minério e sua previsão de res posta na unidade de processamento sempre estiveram incluídas em projetos de mineração e devem fazer parte do modelo de recursos. Com este intuito, este trabalho visa distinguir os diferentes tipos de minério através de suas características mineralógicas, químicas e metalúrgicas. Essas características foram definidas por mapeamento geológico de detalhe, seguidos por análise química dos teores e testes de desempenho que reproduzem em escala de bancada o processo de beneficiamento mineral. Os resultados dos testes de processo foram cruzados com
\end{abstract}

as informações de teores e de geologia para definição de domínios geometalúrgicos. Observou-se a possibilidade de prever desempenhos de recuperação metalúrgica a partir do agrupamento das tipologias de minério em concordância com o mapa geológico. Um modelo geometalúrgico foi gerado, empregando um método da geoestatística não linear para modelagem de variáveis categóricas, i.e. tipos de minério. A metodologia mostrouse adequada, permitindo rapidez na atualização do modelo de blocos.

PALAVRAS-CHAVE: Geometalurgia; Geoestatística; Caracterização de minérios fosfatados.

\section{INDICATORS KRIGING APPLIED TO MODELING OF TYPES OF PHOSPHATE ORE MINE}

\begin{abstract}
Ore characterization and its response in processing plants should be always included in properly designed mining projects and should become part of the resource model. To that purpose, this paper aims to distinguish different ore types through their mineralogical, chemical and metallurgical characteristics. They were defined by descriptive criteria such as geological detail mapping, followed by chemical analysis of ore grade and batch tests which reproduce the mineral processing flowsheet. The samples were tested in the pilot plant and the results of
\end{abstract}

mass and metallurgical yield were crossed with geological information for defining geometallurgical ore zones. It was possible to predict the performances of mass and metallurgical yield starting with grouping the ore types in accordance with the geological map. A geometallurgical model was generated by using a nonlinear geostatistics method for modeling categorical variables, i.e. ore types. This methodology proved to be adequate, permitting fast updating of the block model.

KEYWORDS: Geometallurgy; Geostatistics; Characterization of phosphate ores.

"Trabalho apresentado no Encontro Nacional de Tratamento de Minérios e Metalurgia Extrativa, XXVI, Poços de Caldas, MG, Brasil, 18 a 22 de outubro de 2015." 


\section{INTRODUÇÃO}

A Mina F4 está posicionada no Complexo Alcalino Carbonatítico do Barreiro, no município de Araxá-MG. O Complexo Alcalino do Barreiro possui estrutura dômica com 4,5 km de diâmetro e é constituído por rochas ígneas ultramáficas metassomatizadas (Grossi Sad \& Torres, 1976). Um espesso manto de intemperismo se desenvolveu sobre essas rochas, e concentrou a apatita (mineral minério na lavra de fosfatados) por processos residuais.

A complexidade genética das intrusões alcalinas somada às ações do intemperismo explicam a alta variabilidade do minério e com isso as dificuldades em obter respostas satisfatórias na unidade de processamento mineral. São observadas rochas como, flogopititos de granulação fina, contendo anfibólios, piroxênios e olivinas. Estes flogopititos são recortados por veios, de dimensões centimétricas a métricas, de carbonatitos, foscoritos e apatititos. Em alguns locais, observam-se fragmentos remanescentes de venulações silexíticas, além de barita na massa alterada e/ou em vênulações. As flogopitas alteram-se para vermiculitas; carbonatos (dolomita e calcita), piroxênios e anfibólios são parcialmente substituídos por filossilicatos hidratados (vermiculita, hidrobiotita, cloritas, serpentinas e saponitas).

O beneficiamento do minério é sensível a variações de teores de $\mathrm{MgO}$, marcado pela pres ença de vermiculita, $\mathrm{Fe}_{2} \mathrm{O}_{3}$ e $\mathrm{BaO}$, além de $\mathrm{P}_{2} \mathrm{O}_{5}$, bem como à presença de carbonatos, tornando relevante o conhecimento das variações de composição química e mineralógica ao longo da jazida. Filossilicatos (argilas e micas) interferem no processo de flotação da apatita devido a sua grande capacidade de troca iônica, podendo ser adsorvidos pela apatita alterando sua característica quanto a flotabilidade. Assim como os filossilicatos, os carbonatos também atuam negativamente na flotação da apatita, já que os coletores utilizados são adsorvidos na superfície da apatita em função da presença do íon cálcio, que também está presente na superfície dos carbonatos. Os teores de $\mathrm{Fe}_{2} \mathrm{O}_{3}$ são muito controlados e devem se manter dentro de uma determinada faixa para atender as especificações da etapa posterior à concentração mineral que é a concentração química e do produto final, no caso, fertilizantes. Ou seja, a existência desses minerais exigem alterações importantes na rota de processo. Portanto, as definições de tipologias de minérios e incorporações de dados de processo precisam compor o modelo tridimensional (geometalúrgico), para subsidiar o planejamento de lavra com certa previsibilidade.

Williams e Richardson (2004) definem a geometalurgia como: " seleção de um número de amostras informadas pela geologia para ensaios que determinam parâmetros metalúrgicos dos materiais, onde a interpolação desses parâmetros é utilizada para apoiar o modelo de processos através de técnicas reconhecidas de geoestatística".

Um trabalho específico para caracterização dos tipos de minério foi realizado na mina F4, visando obter o parâmetro de recuperação metalúrgica estimado no modelo de blocos. No entanto, o número de amostras geradas foi inferior ao programado, não cobrindo toda a área de estudo para garantir a interpolação confiável dos valores de recuperação, com isto foram buscadas alternativas para a obtenção do modelo geometalúrgico.

Através da interface multidisciplinar entre geologia, geoestatística e processamento mi neral foi possível propor a criação de um modelo geometalúrgico, onde os valores de recuperação esperados seriam baseados num valor médio para cada um dos domínios tipológicos. 
O modelo foi construído através da aplicação de técnicas de interpolação geoestatística. Essa técnica foi comparada com a modelagem convencional a fim de definir qual se adéqua melhor às rotinas de planejamento de médio e curto prazo usadas na indústria mineral.

\section{MATERIAIS E MÉTODOS}

A metodologia para o desenvolvimento desse estudo compreendeu etapas de campo, laboratório e escritório. A maior parte dos dados foi obtida no ano de 2013.

\subsection{Mapeamento Geológico}

A escala de mapeamento adotada foi de detalhe 1:1000. A interpretação do mapa foi fundamentada no reconhecimento das variações do minério oxidado, em analogia com as ocorrências tipológicas da mina do Barreiro, uma vez que essas minas pertencem à mesma estrutura geológica, e estão contidas na mesma intrusão alcalina.

Para cada tipo de minério identificado, foram descritas as características como: mineralogia, estrutura, textura, granulometria, etc.

\subsection{Definição, Amostragem e Preparação.}

A definição das amostras para compor os testes de bancadas teve como preceito atender as características mineralógicas e químicas do minério oxidado. Ou seja, minério responsável pela produção atual da mina, rico em apatita e com teor inicial (amostra cabeça) de $\mathrm{P}_{2} \mathrm{O}_{5} \geq 5 \%, \mathrm{MgO} \leq$ $3 \%$ e relação $\mathrm{CaO} / \mathrm{P} 2 \mathrm{O} 5(\mathrm{RCP})<1,4$.

As amostras foram obtidas a partir do acervo de testemunhos de sondagem existente e de amostras de curto prazo. Para atender a quantidade em massa necessária para os ensaios de flotação em bancada de $6 \mathrm{~kg}$ a $10 \mathrm{~kg}$, uma ou mais amostras sequenciais com as mesmas características geológicas foram agrupadas compondo um bloco amostral. Cada bloco re cebeu uma redescrição geológica de acordo com os critérios do mapeamento tipológico. A etapa de preparação consistiu-se na homogeneização do material em pilhas prismáticas ou cônicas, quarteamentos e reduções de massa e granulometria até a etapa de análise química dos teores e envio à planta piloto.

Os técnicos das áreas de processo mineral e geologia definiram que seria importante que Destaca-se que as amostras atendem aos seguintes requisitos:

- Todas as amostras separadas sob o ponto de vista geológico. Ou seja, regionalização conforme o mapeamento e amostras georeferenciadas.

- Todas as amostras devem seguir fielmente a rota de caracterização do minério oxidado. Ou seja, para os testes de bancadas utilizar-se-iam somente o coletor óleo de soja (SOS). Isso porque, em paralelo, existem outros coletores sendo testados.

- Parâmetros a serem avaliados: recuperação metalúrgica e recuperação mássica.

\subsection{Preparação do Banco de Dados.}

O banco de dados utilizado foi congelado na data 02/01/2014, sendo constituído por: 
- Dados de geologia: mapeamento geológico, composição de amostras, descrição e preparação de amostras para formação de blocos a serem ensaiados.

- Dados de processo: resultados dos blocos testados em escala de bancada.

As informações foram consolidadas por etapas e em planilha formato Excel. Posteriormente, os dados foram validados e formatados de maneira a atender os padrões de operação do software CAE MINE Studio III ${ }^{\circledR}$ versão 3.20.5321.

O banco de dados contou com 190 resultados de testes de bancada nos blocos amostrados em 2013. Destes, apenas 88 atendiam as premissas estabelecidas no início do trabalho, onde tipo de minério igual oxidado (teor), coletor igual SOS, etc. Os demais não atendiam as premissas por motivos diversos (por exemplo, material retirado em estoque sem georeferenciamento).

Em função da redução do número de testes, foram resgatados ensaios de outras campanhas sob rota de processo de minério oxidado. Foram identificados mais 53 testes entre os anos de 20042006 e mais 28 testes, localizados em arquivos físicos e em condições de uso, relacionados às campanhas de sondagem de 2004. Em resumo, o banco de dados final contou com 88 ensaios referentes ao ano 2013/2014 e mais 81 testes resgatados em campanhas anteriores a 2006, totalizando 169 resultados validados.

Para posicionamento desses blocos no espaço e posterior modelagem, foram calculadas as coordenadas $\mathrm{X}, \mathrm{Y}$ e $\mathrm{Z}$ do centro do bloco com seu teor médio.

\subsection{Tratamento dos Dados}

Esta etapa envolveu:

- Interpretação do mapa geológico.

- Análise exploratória dos dados.

- Confronto das informações geológicas e metalúrgicas.

- Agrupamentos de domínios geoestatísticos.

- Definição dos parâmetros para modelagem, i.e, tipos de minério e

- Definição da metodologia para incorporação das variáveis categóricas.

\subsection{Validação dos Resultados}

Comparação de metodologias (modelagem convencional vs modelagem estatística).

\section{RESULTADOS E DISCUSSÃO}

\subsection{Análise dos Domínios Geológicos}

Como ponto de partida, as tipologias de minério foram definidas por similaridade com os tipos de minério presentes na mina do Barreiro. À medida que o mapeamento geológico se aprofundou, características intrínsecas do minério da mina F4 foram sendo acrescentadas e/ou redescritas. Algumas tipologias tiveram sua ocorrência limitada a horizontes mais superficiais, como o caso da tipologia Oxi-C-CiSx (V). Outras sofreram modificações na nomenclatura. Tipologias antes denominadas de oxidado devido a sua característica química semelhante ao minério oxidado foram 
renomeadas para silicatado, em função dos estudos mineralógicos e avanços no mapa geológico que previram presença de minerais silicáticos. Ou seja, o critério químico serviu a princípio para individualização dos tipos de minério, prevalecendo posteriormente sobre este, a mineralogia e os resultados de recuperação. Algumas amostras foram enviadas ao laboratório de caracterização tecnológica da Universidade de São Paulo (LCT/USP) para identificação e comprovação mineralógica.

O mapa utilizado neste estudo de caso foi atualizado em abril de 2014 e contava com oito tipologias, a saber: (1) estéril argiloso, (2) oxidado compacto com silexito (Oxi-C-Sx), (3) oxidado semi-compacto (Oxi-S), (4) silicatado friável e plástico (Sil-F-PI), (5) silicatado compacto com silexito (Sil-C-Sx), (6) silicatado friável com silexito e barita (Sil-C-CiBaSx), (7) silicatado friável com caulim (Sil-F-Cau), (8) silicatado friável (Sil-F).

As tipologias 5, 6, 7 e 8 serão tratadas como uma única unidade, uma vez que fazem parte da derivação de uma unidade maior, denominada de silicatada.

É possível simplificar o mapa geológico, em função das observações de campo e da interpretação do mapa em dois grupos principais de tipos de minério de acordo com suas características. Um grupo é definido pelo prefixo oxi (oxidado). Esses são materiais constituídos basicamente por apatita, oxi-hidróxidos de ferro, quartzo, vermiculita e magnetita. Apresentam granulometria arenosa, fragmentos de silexito e textura rugosa. $O$ outro grupo (tem o prefixo sil) e é marcado pela presença de minerais silicatados. Os materiais silicatados se distinguem por apresentar uma apatita mais liberada, flogopita, vermiculita, anfibólios, piroxênios, clorita e feldspato (Figura 1).

Sob essa ótica, a interpretação do mapa permite regionalizar os tipos de minério em dois macros grupos mineralógicos (Figura 1).

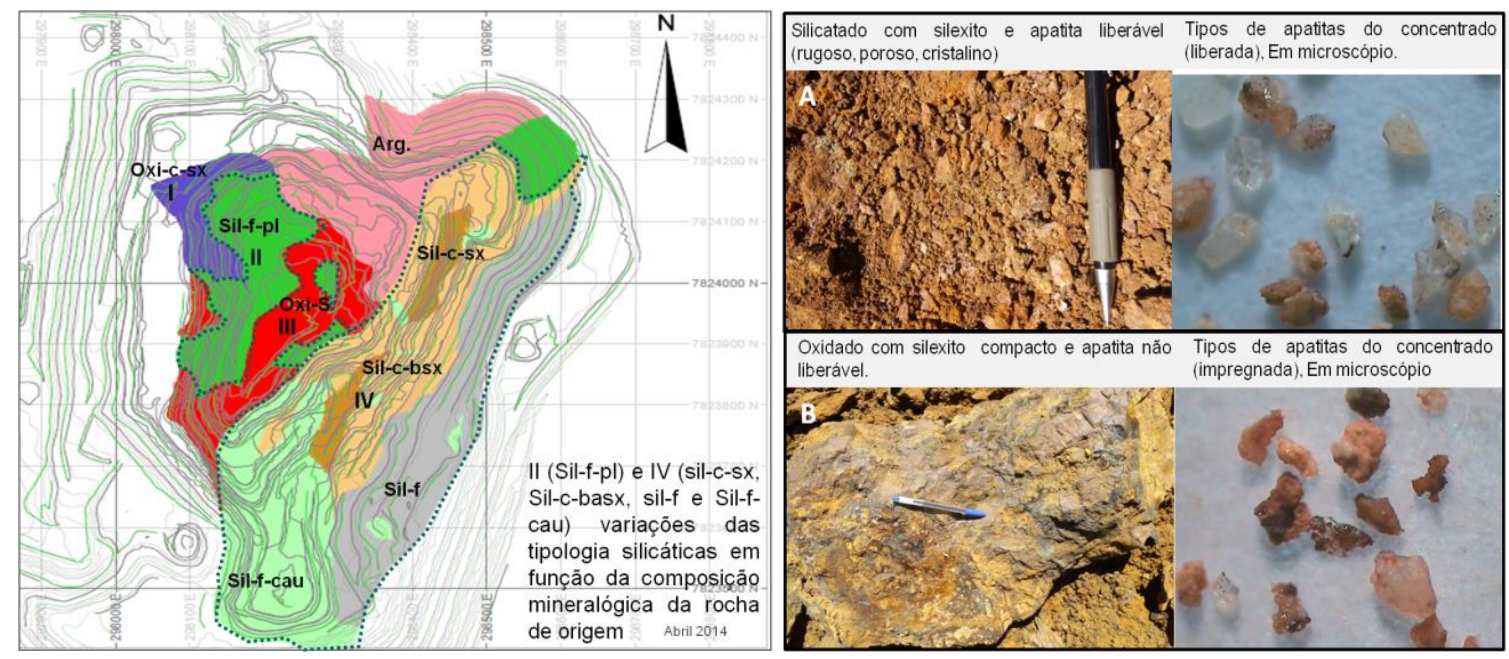

Figura 1: Na esquerda, regionalização das tipologias de minério. Dois macro-domínios: grupo dos oxidados (I e III) e grupo dos silicatados (II e IV). Na direita, apatita liberada (A) e mista (B) descritas em microscópio binocular.

\subsection{Análise dos Domínios Estatísticos}

A análise estatística descritiva dos dados teve início com os histogramas da variável recuperação metalúrgica separada por cada tipologia de minério descrita no mapa geológico. Os histogramas também foram individualizados por campanhas, ou seja, as amostras dos testes 
anteriores a 2006 foram separadas das amostras de 2013/2014 para a análise dos dados. Observouse nos histogramas, que as campanhas antigas apresentaram sumário estatístico diferente dos resultados atuais. Um exemplo é a média da recuperação metalúrgica que passou de $58,6 \%$ para 41,4\% nas campanhas 2013/2014. Acredita-se que essas diferenças ocorreram em função de alterações pontuais na caracterização do minério nos testes de bancada nas campanhas anteriores. Como não foi possível rastrear e detalhar as etapas do procedimento operacional (tempo de moagem, coletor, etc.) aplicado nas campanhas antigas, optou-se em utilizar somente dados das campanhas 2013 no tratamento estatístico.

Os histogramas de recuperação apresentaram médias e variâncias distintas para os diferentes tipos de minério mapeados. Avaliando somente a média entre as tipologias, foi possível identificar dois grupos estatísticos; os que apresentam recuperação metalúrgica maior que 45 e as tipologias com médias de recuperações metalúrgicas menores que 45.

Este fato conduziu a uma nova avaliação onde as tipologias foram separadas em função dos valores de recuperação metalúrgica (Figura 2), sendo resumidas em dois domínios: as tipologias de prefixo oxi (tipologias I, III e V) e as de prefixo sil (tipologias II e IV), conforme visto na Figura 1.
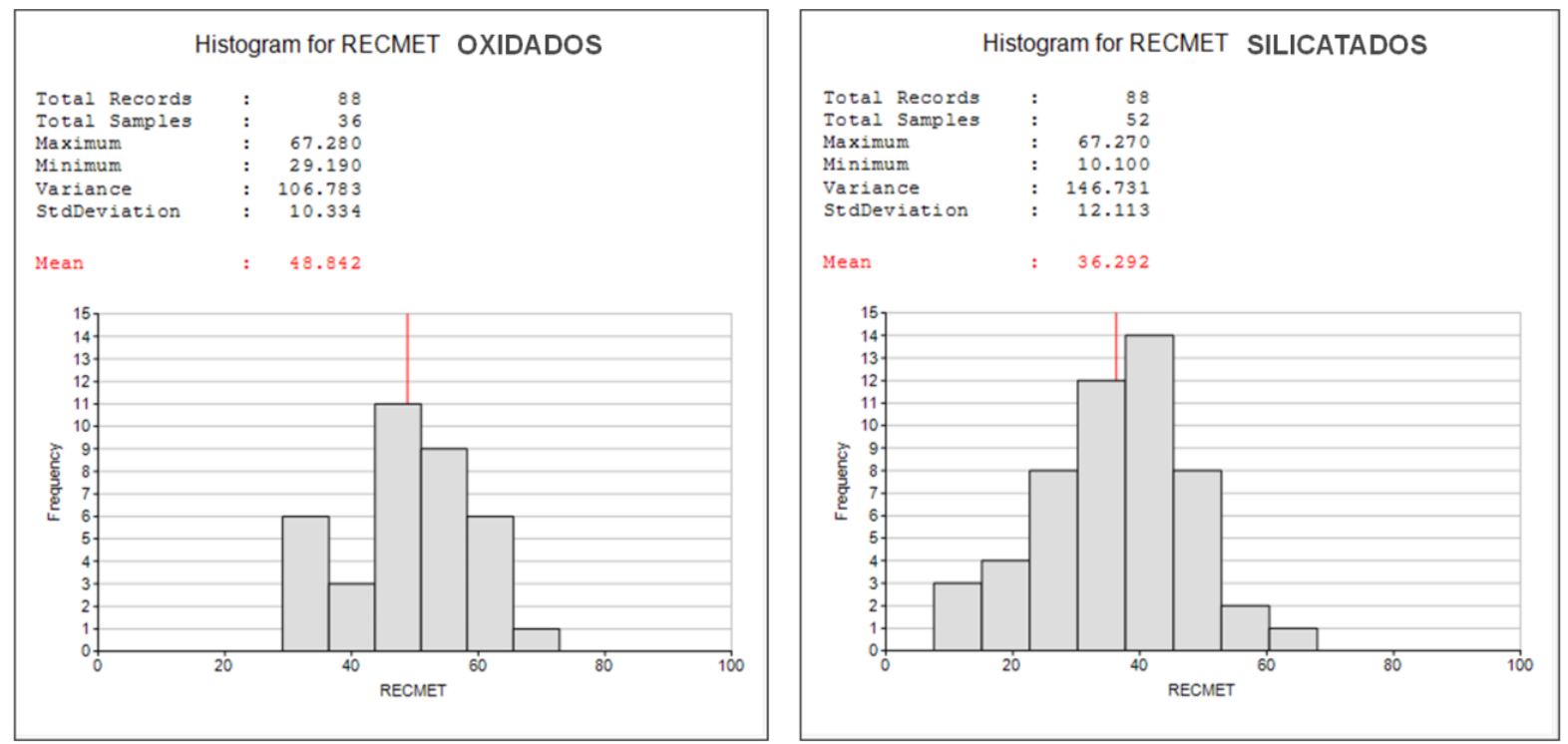

Figura 2: Histograma de recuperação metalúrgica das tipologias oxidado e silicatado.

Em função dessas avaliações, a Análise de Variância (ANOVA) foi utilizada para auxílio na definição de grupos. A análise da variância aborda a situação comum em que dois ou mais grupos devem ser comparados com base em alguma medida de localização. Métodos clássicos são utilizados para comparar, inicialmente, as médias de grupos independentes sob a suposição de normalidade das distribuições de probabilidade.

Embora o objetivo seja testar a hipótese das médias serem iguais (hipótese nula), o processo se dá pela decomposição da variância total existente entre as observações. Ou seja, decomposição da variação total da variável resposta (recuperação metalúrgica) em partes que podem ser atribuídas aos tratamentos/tipologias (variância entre) e ao erro experimental (variância dentro).

Este tipo de situação pode ser verificado através do teste estatístico, tido como teste $\mathrm{F}$, que avalia o fator (F), indicando o tamanho da diferença entre os grupos, em função do tamanho da variação dentro de cada grupo. 
Considerando uma variável de interesse com média $\mu$ e variância $\sigma^{2}$ temos dois estimadores da variância $\sigma^{2}$ :

$S b^{2}=$ dispersão entre os grupos

$\mathrm{Sw}^{2}=$ dispersão dentro dos grupos, onde, fator $\mathrm{F}=\mathrm{Sb}^{2} / \mathrm{Sw}^{2}$

O teste $\mathrm{F}$ foi utilizado para comparar as variâncias. O software utilizado para essa análise foi o Statistica ${ }^{\circledR}$. O valor do $\mathrm{p}$-value obtido foi menor que nível de significância $\alpha$ estabelecido (5\%). 0 nível de significância indica a probabilidade de se cometer um erro tipo 1 . 0 erro tipo 1 se refere à rejeição da hipótese nula quando esta é verdadeira.

Quando a hipótese nula de médias iguais é verdadeira, Sb2 e Sw2 (dispersão dos quadrados entre os grupos e dispersão dos quadrados dentro dos grupos) devem ter valores semelhantes, e o teste estatístico deve ter resultado próximo de um. $\mathrm{O}$ valor de $\mathrm{F}$ computado neste trabal ho mostrouse bem acima de um (Figura 3) e maior que of tabelado 2,486 (dados obtidos na tabela de Fisher). Portanto, a hipótese nula foi rejeitada, ou seja, ficou evidenciado que existem diferenças significativas entre pelo menos um par de médias dos tratamentos, i.e, tipologias de minério, quando estas foram analisadas sob o ponto de vista da variável resposta recuperação metalúrgica.

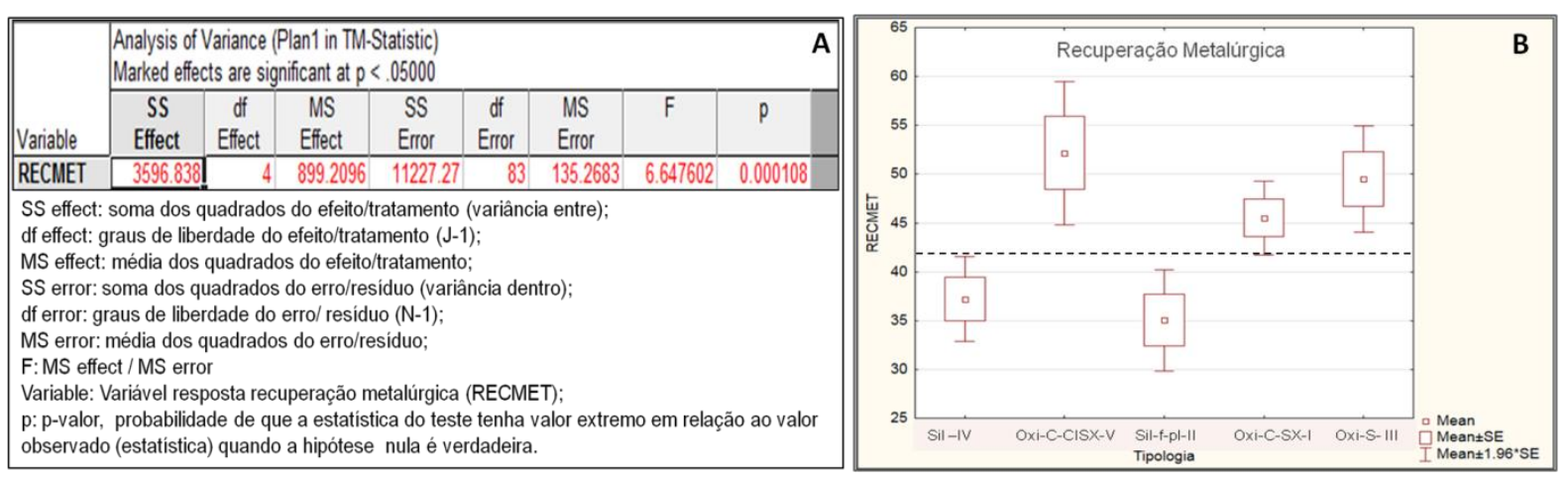

Figura 3: Em A resultado do teste $F$ e em B box plot das tipologias de minério. $O$ gráfico apresenta a recuperação metalúrgica média para as diferentes tipologias.

A verificação do segundo pressuposto da ANOVA é a da homocedasticidade, sendo que esta pode ser medida por meio de análise gráfica. A Figura 3 apresenta o box-plot dos grupos de tipologias de minério e seus resíduos. Se a condição de homogeneidade da variância (homocedasticidade) fosse verdadeira, esperaríamos que os box-plots fossem semelhantes. Issoé o mesmo que dizer que a variabilidade é a mesma em todas as caixas. No entanto, o que se observou foi uma condição de heterocedasticidade, ou seja, a variabilidade é diferente entre os boxes. Is to é mais um indício de diferença estatística entre os grupos ou os dois macros grupos (oxidados e silicatados).

O tratamento estatístico previu dois grupos distintos. Esse fato permitiu concluir que embora o número de amostras de ensaios padrão não seja suficiente para interpolação bloco a bloco do "valor" recuperação metalúrgica e mássica (como é feito com o teor), é suficiente para confirmar a existência de um comportamento metalúrgico específico para cada um dos dois grupos: tipologia oxidado e a tipologia silicatado. Esse fato é corroborado pelas informações geológicas que evidenciaram claramente as diferenças mineralógicas desses dois domínios tipológicos. 
Dessa forma, propõe-se a criação de um modelo 3D geometalúrgico, onde os valores de recuperação esperados seriam baseados num valor médio para cada um dos domínios tipológicos. As vantagens desse modelo é que ele traz uma informação quantitativa de processo, e uma informação geológica em constante atualização. Isso é interessante, pois permite a adequação do modelo em função dos avanços do mapa geológico independente das etapas laboratoriais. Vale ressaltar que as etapas laboratoriais são de extrema importância e devem, sempre que possível, compor a rotina da modelagem a fim de confirmar os fatos observados e/ou trazer novas informações. Em suma, modela-se a tipologia sem atribuir a cada bloco um valor de recuperação mássica no processo. Faz-se uma estimativa de recuperação global por domínio.

Sob essa perspectiva, a metodologia krigagem dos indicadores foi empregada para modelagem das variáveis categóricas tipos de minério. Journel (1983) apresentou a krigagem indicadora como uma proposta para construir uma função de distribuição de probabilidades acumuladas através de uma transformação não-linear. A interpolação não-linear é uma tentativa de estimar a expectativa condicional de um teor em um local, ao invés de simplesmente prever o próprio teor (Goovaerts, 1997). Desta forma, para cada ponto estimado pela krigagem dos indicadores, são gerados valores de probabilidade de o mesmo pertencer a cada teor de corte ou cada uma das categorias (no caso, tipos de minérios). Assim, o banco de dados foi categorizado de forma binária, onde grupo oxidado recebeu codificação " 1 " e o outro grupo codificação " 0 ". As informações do mapa geológico também compuseram a base de dados para interpolação dos tipos de minério, sendo as superfícies de mapeamento transformadas em um grid de pontos de $10 \mathrm{~m} \times 10 \mathrm{~m} \times 10 \mathrm{~m}$. A extrapolação em profundidade de $10 \mathrm{~m}$ corresponde à altura de uma bancada da mina e é mais conservadora do que as espessuras das camadas das tipologias.

Os semivariogramas horizontais e o vertical dos indicadores foram testados. O melhor ajuste na horizontal foi na direção 67,5 ㅇ semelhante ao trend dos contatos no mapa geológico. 0 processo de interpolação da krigagem dos indicadores é controlado pelos modelos ajustados aos variogramas experimentais. O modelo dos indicadores das variáveis categóricas foi gerado para um tamanho de blocos de $25 \times 25 \times 10$ no software Studio III Caemine ${ }^{\circledR}$.

Com o intuito de validar o modelo probabilístico, seções geológicas foram criadas para a modelagem convencional dos indicadores. As seções horizontais foram interpretadas segundo formas concêntricas tendo como origem as informações das amostras e do mapeamento geológico. A delineação dos contatos (individualização dos dois grupos) foi baseada em um princípio similar à metodologia de criação de mapas de isolinhas, ou seja, as amostras com os indicadores 0's e 1's foram circundadas, respectivamente, com a isolinha de valor zero e a isolinha de valor um. A validação visual por seção mostrou uma boa similaridade entre os modelos (Figura 4). É possível observar no gráfico de proporções dos indicadores que o modelo dos indicadores apresentou-se mais aderente aos dados (Tabela 1).

Tabela 1: Número de pontos e porcentagem dos indicadores no banco de dados e nos modelos de blocos.

\begin{tabular}{|c|c|c|c|c|c|c|}
\hline & \multicolumn{5}{|c|}{ No PONTOS } \\
\cline { 2 - 7 } & \multicolumn{2}{|c|}{ BANCO DE DADOS } & \multicolumn{2}{c|}{ MODELO IK } & MODELO GEOLÓGICO \\
\hline INDICADOR & $\mathbf{0}$ & $\mathbf{1}$ & $<\mathbf{0 . 5}$ & $\mathbf{0 . 5}$ & $\mathbf{0}$ & $\mathbf{1}$ \\
\hline No PONTOS & 40 & 14 & 12039 & 4023 & 8303 & 3715 \\
\hline PORCENTAGEM & $74.1 \%$ & $25.9 \%$ & $75.0 \%$ & $25.0 \%$ & $69.1 \%$ & $30.9 \%$ \\
\hline
\end{tabular}




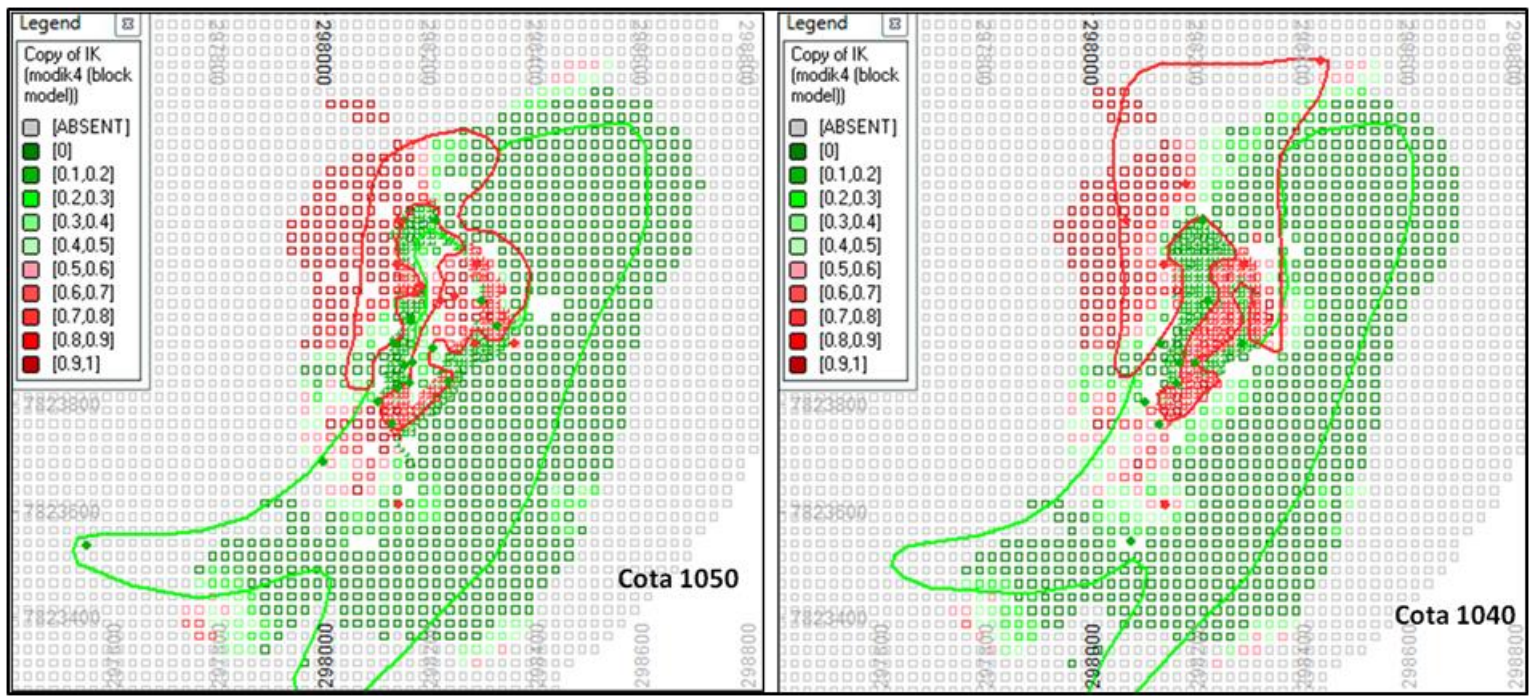

Figura 4: Seções horizontais, cota 1050 e 1040. Linhas de contorno da seção geológica interpretada sobreposta à seção equivalente no modelo krigado.

\section{CONCLUSÕES}

A integração das atividades de geologia (mapeamento geológico de detalhe, caracterização mineralógica, etc.) com os estudos de processamento mineral é valiosa para definição das características mineralógicas da jazida e a definição dos tipos de minério. Os domínios tipológicos têm características mineralógicas, químicas e físicas próprias com impactos significativos na concentração mineral. Reconhecer essas características ajuda na previsibilidade do desempenho do processo a tipos e ganhos de produtividade no planejamento de lavra e beneficiamento.

A aplicação da krigagem dos indicadores para as tipologias se mostrou uma boa alternativa para compensar o baixo número de ensaios e ao mesmo tempo garantir uma resposta metalúrgica importante. A comparação visual através de seções horizontais cotadas a cada $10 \mathrm{~m}$ entre o modelo convencional e o modelo dos indicadores validou a técnica aplicada. A principal vantagem do modelo matemático foi dispensar a atividade manual para gerar seções e sólidos, etapa muito demorada na modelagem convencional. Além de ser mais rápido, este modelo permite a automatização das rotinas através de scripts e macro para atender as demandas do planejamento de curto prazo. Outra vantagem da modelagem probabilística dos tipos geometalúrgicos é o uso interativo dos valores de probabilidade dos blocos para ajuste e adequação dos contatos. 0 geomodelador pode ser mais conservador ou mais otimista na determinação dos limites usando medidas de probabilidade.

\section{REFERÊNCIAS}

1. Goovaerts, P. Geostatistics for Natural Resources Evaluation. Oxford University Press, New York. 1997; 483p.

2. Grossi Sad J H \& Torres, N. Geology and mineral resources of the Barreiro Complex, Araxá, MG. 10 Congr. Int. Cabonatitos, Poços de Caldas, Brazil. 1976.

3. Journel, A. G. Non parametric estimation of spatial distributions. Journal of International 
Association for Mathematical Geology. 1983; v.15, n.3, 445-468p.

4. Williams, S. R. e Richardson, J. M. Geometallurgical Mapping: A New Approach That Reduces Technical Risk. Proceedings 36th Annual Meeting of the Canadian Mineral Processors. 2004; Paper 16, 28p. 